\title{
Differential selection pressures result in a rapid divergence of donor and refuge populations of a high conservation value freshwater fish Coregonus lavaretus (L.)
}

\author{
J. Peter Koene ${ }^{1}$ (D) $\cdot$ Marco Crotti ${ }^{2} \cdot$ Kathryn R. Elmer $^{2} \cdot$ Colin E. Adams $^{1}$
}

Received: 11 January 2019 / Accepted: 5 June 2019 / Published online: 15 June 2019

(c) The Author(s) 2019

\begin{abstract}
As a conservation measure to protect European whitefish in Scotland, a translocated population was established in Loch Sloy from Loch Lomond stock between 1988 and 1990. Previous study has assumed that current morphological differences between adults from the donor and refuge lakes have arisen through phenotypic plasticity. The present study compared the morphologies of whitefish at three life stages: alevins and fry raised in a common garden, and wild-caught adults. Alevins were clearly distinguishable by their lake of origin. Loch Sloy alevins were distinguishable also by family, although this was not the case for Loch Lomond. Differential allometric trajectories facilitated the persistence of morphological differences associated with lake of origin through the fry stage into adulthood. Overall, the whitefish from Loch Lomond displayed morphologies associated with pelagic feeders, while the more robust heads and ventrally positioned snouts of the Loch Sloy whitefish conformed to expectations for more benthic feeding habits. That differences between populations were present not only in wild adults, but also in alevins and fry from a common garden setup, strongly suggests that the divergence between populations is due to inheritance mechanisms, rather than differential plastic responses, and questions the effectiveness of translocation as a conservation measure.
\end{abstract}

Keywords Whitefish · Conservation · Translocation · Divergence $\cdot$ Morphology

Electronic supplementary material The online version of this article (https://doi.org/10.1007/s1068 2-019-09995-y) contains supplementary material, which is available to authorized users.

J. Peter Koene

j.peter.koene@gmx.at

1 Scottish Centre for Ecology and the Natural Environment (SCENE), University of Glasgow, Rowardennan, Glasgow G63 0AW, UK

2 Institute of Biodiversity, Animal Health and Comparative Medicine, College of Medical, Veterinary and Life Sciences, University of Glasgow, Glasgow G12 8QQ, UK 


\section{Introduction}

Intraspecific phenotypic variation is a common feature of fishes of the fragmented, heterogeneous environments of lakes in regions that were recently glaciated (Carvalho 1993; Klemetsen 2013), where, generally, species diversity is low, resulting in opportunities to exploit alternative foraging resources (Gíslason et al. 1999). Such lakes are young and often geologically isolated, with attendant low dispersal of freshwater fishes. This creates conditions enabling intraspecific trophic specialisation and diversification of the few species to have colonised such systems successfully (Schluter 2000). Occurring with relative rapidity (Bernatchez and Wilson 1998), differential resource use, typically across alternative littoral (benthic) and pelagic habitats, is considered to be a driving force behind the diversification in morphology of a number of fish species (Smith and Skúlason 1996; Vonlanthen et al. 2009; McPhee et al. 2012). Disruptive selection may promote and maintain intraspecific phenotypic structuring expressed as specialists in alternative foraging strategies, growth rates, or spawning times or habitats, with different morphological features (Adams et al. 2016; Brown and Scott 1994; Vonlanthen et al. 2009). This may occur particularly in heterogeneous environments, when alternative morphologies confer greater fitness advantages upon trophic specialists than an intermediate might do (Draghi and Whitlock 2012; Fusco and Minelli 2010). When such specialisms result in reproductive isolation, intraspecific divergence may become firmly established (Schluter 2009).

Phenotypic plasticity, the capacity of a given genotype to express alternate phenotypes in response to different environmental conditions, has been proposed as a medium through which adaptive divergence of phenotype across alternative ecological niches may occur (West-Eberhard 1989; vide Levis and Pfennig 2016 for recent review). Adaptive plasticity in morphology has been shown to occur in a number of fish species from recently glaciated lake systems (vide Robinson and Parsons 2002 for review). It has been suggested that by broadening the range of expressed intraspecific phenotypes, plasticity can influence both the direction and the rate of evolution, and thereby shape a species' future responses to selective pressures (West-Eberhard 1989; Price et al. 2003). Plasticity may, in some instances, constrain genetic change by insulating the genotype from natural selection (Hendry 2016), and, depending on the environments, it can just as easily make divergent phenotypes more similar as it can drive them further apart (Ghalambor et al. 2007). But, by enabling phenotypes more closely to match local environmental conditions, plasticity may play a substantial role in a species' success at adapting to a changing environment or colonising novel habitats (Parsons and Robinson 2006; Januszkiewicz and Robinson 2007). Thus, it is argued that plasticity may play a critical role in facilitating incipient ecological speciation (e.g. Adams and Huntingford 2004; Nosil 2012).

Diversity of phenotype may also be achieved with rapidity by other mechanisms. Disruptive selection can act upon the natural variation of phenotypic traits and lead to the differential fixation of the underlying alleles (Schluter 2009). The extent of genetic variation with which natural selection has to work may influence the direction of phenotypic change, and founder effects, in which only a subset of the genetic variation of the ancestral population is found in a colonising population, are well documented (Matute 2013). Instead of adaptive evolution by natural selection, neutral genetic drift commonly accompanies founder events, and can lead to divergent phenotypes between ancestral and colonising populations (Matute 2013). Differences in transgenerational parental and epigenetic effects, such as gamete provisioning or the regulation of gene expression may provide means by which disruptive selection might consummate divergence between 
related populations (Räsänen and Kruuk 2007; True et al. 2004; Wiegand et al. 2007). Such effects can be adaptive, and through inheritance, perpetuate parents' phenotypic traits advantageous to a particular environment to their offspring (Heard and Martienssen 2014).

The European whitefish, Coregonus lavaretus (L.), is one of the rarest freshwater fish species in the UK, native to only seven lakes across England, Scotland and Wales. These seven populations show some degree of genetic and morphological differentiation between each other (Beaumont et al. 1995; Hartley 1995; Etheridge et al. 2012). The population in Loch Lomond, one of only two lakes in Scotland to hold native populations of whitefish, became increasingly threatened over the past century and a half by anthropogenic disturbances from several large engineering works (water-supply and hydro-electric schemes on inflows and outflows, with direct consequences for water levels in the lake), pollution, and high leisure use (Maitland and Lyle 2013). From the 1980s the invasive ruffe, Gymnocephalus cernuus, appeared in the lake and has since become abundant (Adams and Maitland 1998); it is a major consumer of whitefish ova in Loch Lomond (Adams and Tippett 1991). As a conservation measure, between 1988 and 1990 a refuge population was established at nearby Loch Sloy, in which ruffe remain absent, with the translocation of 12,227 fry from a mixed batch of parents originating from Loch Lomond plus a further 85 adults (Maitland and Lyle 2013) with care taken to preserve allelic richness (Thompson et al. 2008). Subsequent work has demonstrated that the translocated population became established and is now flourishing (Adams et al. 2014) after five or six generations (Brown et al. 1991).

A comparative study of the whitefish populations from Lochs Lomond and Sloy showed clear morphological divergence of the refuge from the donor population (Etheridge et al. 2010). That study examined only adults, caught in winter $2005 / 2006$, and found they differed significantly in head shape: the Loch Sloy population exhibited shallower heads, more elongated snouts and mouths, and more posteriorly positioned eyes than did the Loch Lomond population. The underlying process leading to differing morphologies was unknown, but the authors suggested, as possibilities, either phenotypic plasticity, genetic change resulting from differential selection, or a combination of both (Etheridge et al. 2010). Phenotypic plasticity is supported by the fact that coregonid species have been shown to exhibit high levels of phenotypic plasticity (Lundsgaard-Hansen et al. 2013), and that plastic effects have been described in other fish translocations (e.g. Lema and Nevitt 2006). Individuals with high capacities for plasticity may be better prepared than those with lower capacities to exploit a broader range of niches if they overlap with their reaction norms (i.e. their ranges of plastic phenotypes) (Schneider and Meyer 2017). So, it may be that survivors of translocations are those with the highest capacity for plasticity and, thus, most able to adapt in a new environment (Parsons and Robinson 2006). However, there is evidence that plasticity capacity may be diminished through genetic assimilation (Parsons et al. 2011), which might be expected in an established population (Pfennig et al. 2010). Etheridge et al. (2010) tested for neither plasticity nor genetic divergence, but since the donor population in Loch Lomond had been long-established, and candidates for relocation to Loch Sloy were not chosen for their capacity for plasticity (Maitland and Lyle 2013), it seems at least equally likely that morphological divergence has some selective genetic or epigenetic basis. The environments of the donor and refuge lakes show some differences in bathymetric characteristics, such as depth and surface area, both of which are greater in Loch Lomond than Loch Sloy. Proportions of pelagic (greater in Loch Lomond) and littoral zones (greater in Loch Sloy) are factors that have been strongly associated with population level eco-morphological traits and variability in postglacial fishes (Recknagel et al. 2017), either through plastic response or heritable genetic or epigenetic changes. 
The aim of the present study was to examine the proximate origin of the morphological divergence that has previously been reported between the whitefish populations of Lochs Lomond and Sloy. Specifically, we aimed to test whether the morphological differences between adult fish in the donor (Loch Lomond) and refuge (Loch Sloy) populations are the result of plasticity or genetic change through differential selection using a common-garden experiment. Shape and allometric slope differences were compared between populations derived from the two lakes at three life stages. Following the lifestage terminology of Thorstad et al. (2011), alevins (the stage post-hatch but pre-feeding) and fry (the stage from first exogenous feeding but before the end of the first growth season) were raised from eggs in the laboratory; adults (above the age of expected sexual maturity) were caught in the wild. To examine whether differences between fish in the donor and refuge populations in the wild are the result of genetic change between populations, this study tests the hypothesis: that the morphology of the newly hatched and unfed alevins and fed fry, reared in a common environment, will differ by lake of origin.

\section{Materials and methods}

\section{Study sites}

Both study sites are in Scotland, UK. Loch Lomond $\left(56^{\circ} 05^{\prime} \mathrm{N} ; 04^{\circ} 36^{\prime} \mathrm{W}\right)$ has a surface area of $71 \mathrm{~km}^{2}$ and a maximum depth of $190 \mathrm{~m}$. Loch Lomond's three basins are well connected and whitefish within show only weak intraspecific structuring (Adams et al. 2016). Loch Sloy $\left(56^{\circ} 16^{\prime} \mathrm{N} ; 04^{\circ} 47^{\prime} \mathrm{W}\right)$ lies to the northwest of Loch Lomond and is part of the Lomond catchment. Enlarged by damming as part of a hydroelectric scheme, it now covers about $1 \mathrm{~km}^{2}$ to a maximum depth of $40 \mathrm{~m}$. The whitefish population in Loch Sloy is completely isolated from that of Loch Lomond by the dam and turbines, with no possibility of interlacustrine migration.

\section{Sample collection: adults for morphometrics}

Three benthic $(1.5 \mathrm{~m} \times 30 \mathrm{~m})$ and one pelagic $(6 \mathrm{~m} \times 30 \mathrm{~m})$ Nordic-pattern monofilament gill nets with 12 panels of 5-55 mm mesh size (Appleberg et al. 1995) were deployed overnight in the central basin of Loch Lomond, in locations where individuals forming the original donor population had also been collected (Lyle pers. comm.), from 24th to 25th August 2017, and off the southwestern bank of Loch Sloy from 9th to 10th October 2017. Care was taken to ensure similarity of habitats sampled between the two lakes to avoid inadvertent sampling of divergent phenotypes (see supplementary material). Eight adult whitefish were captured in Loch Lomond and 17 from Loch Sloy. The fish were photographed individually, in the same orientation, with their left sides facing upwards, on a measuring board using a Canon EOS 35D dSLR camera with a Canon EF-S 18-55 mm f/3.5-5.6 Zoom lens on a Manfrotto tripod. Additionally, photographs of 80 whitefish from Loch Lomond and 22 from Loch Sloy, captured between 2008 and 2010, were drawn from a previous study (Adams et al. 2016). 


\section{Sample collection: eggs for common garden}

Four benthic gill nets measuring $1.5 \mathrm{~m} \times 30 \mathrm{~m}$ with a $38 \mathrm{~mm}$ single mesh size were used to capture adult whitefish on spawning grounds at locations in Loch Lomond overnight from 15th to 16th January 2018 and in Loch Sloy, overnight from 11th to 12th January 2018 (spawning season). Twenty adults were taken from Loch Lomond, and 18 from Loch Sloy. From Loch Lomond, the eggs of four ovulating females were fertilised by five males, giving three full-sibling and two half-sibling groups. Five ovulating females from Loch Sloy were stripped of their eggs by flank massage and fertilised with milt from six males at the capture site to give four full families and two half-sibling groups. Because whitefish are a protected species of high conservation value in Scotland, sample sizes were kept deliberately low; eggs not used in this study were given to a local conservation programme (Loch Lomond Fisheries Trust 2018). Females whose body shapes were distorted due to ovulation were not photographed, but 16 other adult fish from Loch Lomond and 13 from Loch Sloy were photographed as above and included in the analysis.

\section{Husbandry}

Eggs from each family were transported to the Scottish Centre for Ecology and the Natural Environment, University of Glasgow, and incubated in a temperature-controlled recirculation unit. Adapted from the design of Rottman and Shiremann (1988), the unit consisted of round-bottomed plastic bottles (ca. $500 \mathrm{ml}$ ) with a constant flow of water from a header tank that was refilled by pumping from a sump tank. The water was from Loch Lomond and was maintained at $4-5{ }^{\circ} \mathrm{C}$; the current in the incubation flasks was just strong enough to keep all eggs in motion.

Hatching occurred between 14th March and 11th April 2018. Alevins were placed by family into identical glass aquaria measuring $35 \mathrm{~cm} \times 30 \mathrm{~cm} \times 30 \mathrm{~cm}$ with a flowthrough system using water pumped directly from Loch Lomond at ambient temperatures and exposed to a daily photoperiod of $10 \mathrm{~h}$ light. As natal yolk was depleted and the developing fry (from the same cohort as the sampled alevins, but at a later stage of development) began exogenous feeding, a mixture of finely puréed commerciallybought lambs' liver (Marks and Spencer PLC) and ZM-100 fry flakes (ZM Systems) was given four times daily from 14 to 47 days from the start of the hatching period.

From day 48 , the surviving fry from all families were pooled together according to lake of origin and then randomly redistributed into identical, flow-through, cylindrical experimental tanks measuring $38.5 \mathrm{~cm}$ deep with a $35 \mathrm{~cm}$ diameter, two tanks per lake. Water was pumped directly from Loch Lomond at ambient temperatures and given a moderate directional current, and artificial lighting matched the natural photoperiod for this latitude $\left(56^{\circ} \mathrm{N}\right)$. Each tank was provided with an airstone and no other ornamentation. Fish were fed twice a day on a mixture of roughly puréed lambs' liver (Marks and Spencer PLC) and ZM-300 fry flakes (ZM Systems).

\section{Sample collection: juveniles for morphometrics}

Fourteen days from the start of the hatching period, 15 alevins randomly selected from each of the five largest families (two from Loch Lomond; three from Loch Sloy), which 
could most easily sustain losses, were euthanised in a benzocaine solution, photographed individually, in the same orientation, with their left sides facing upwards, on a purpose-built photographic stage, with measuring board, using a Canon EOS 35D dSLR camera with a Canon EF-S $60 \mathrm{~mm}$ f/2.8 Macro lens. On day 120, all surviving fry-12 originating in Loch Lomond and nine originating in Loch Sloy-were euthanised in a benzocaine solution and photographed similarly.

All work described here was conducted under UK Home Office Licence No. PPL 70/8794 (animal experimentation) and Scottish Natural Heritage licence 103925 (rare species collection).

\section{Geometric morphometrics and statistical analysis}

Digital images were made into thin plate spline (TPS) files with tpsUtil (Rohlf 2017b). Landmarks representing homologous points (Takács et al. 2016) were identified separately for alevins (Fig. 1) and fry and adults (Fig. 2), then scale-calibrated and digitised using tpsDig2 (Rohlf 2017a). Given their early stage of development and that a yolk sac remained at this developmental stage, alevins were landmarked differently from fry and adults. Each life stage was analysed separately from the others, as either conditions or landmarks were deemed not to be directly comparable. In order to increase sample size, all photographs of adults were treated together, regardless of when they were taken, and despite the differing numbers of generations since the translocation (four for the earliest photographs through to five or six for the later ones).

The package 'Geomorph' (Adams et al. 2019) was used with 'RRPP' (Collyer and Adams 2019) in $R$ (R Core Team 2019) for all geometric morphometric and multivariate analysis. Confounding variation resulting from fish image size, position and orientation was reduced with Procrustes superimpositions (Mitteroecker and Gunz 2009). Morphological variation was explored through principal component analyses (PCA) conducted for each life stage. Where non-biological lunate distortion was pronounced (sensu Valentin et al. 2008), residuals from a regression of the Procrustes coordinates on the affected PC were used (Hooker et al. 2016). Effects of log centroid size of individuals on shape, defined by Procrustes coordinates, (allometry) were tested at each life stage by population and, in the case of alevins, family for homogeneity of slope with a 1000-round randomized residual permutation ANOVA.

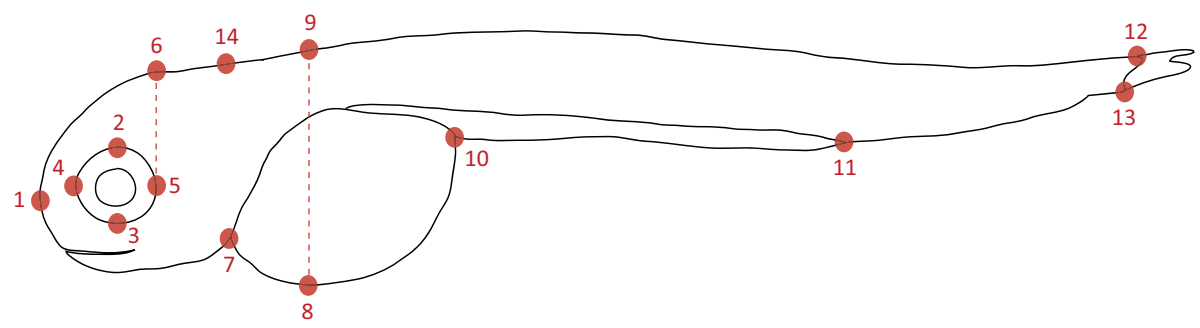

Fig. 1 Landmarks used for geometric morphometrics analysis of C. lavaretus alevin shape: (1) tip of snout; (2-5) superior, inferior, anterior and posterior of eye; (6) dorsal surface perpendicular to (5); (7) anterior of yolk sac; (8) deepest point of yolk sac; (9) dorsal surface perpendicular to (8); (10) posterior of yolk sac; (11) anus; $(12,13)$ dorsal and ventral insertions of caudal fin; (14) dorsal posterior of skull. Perpendicular alignments between landmarks are indicated with broken lines 


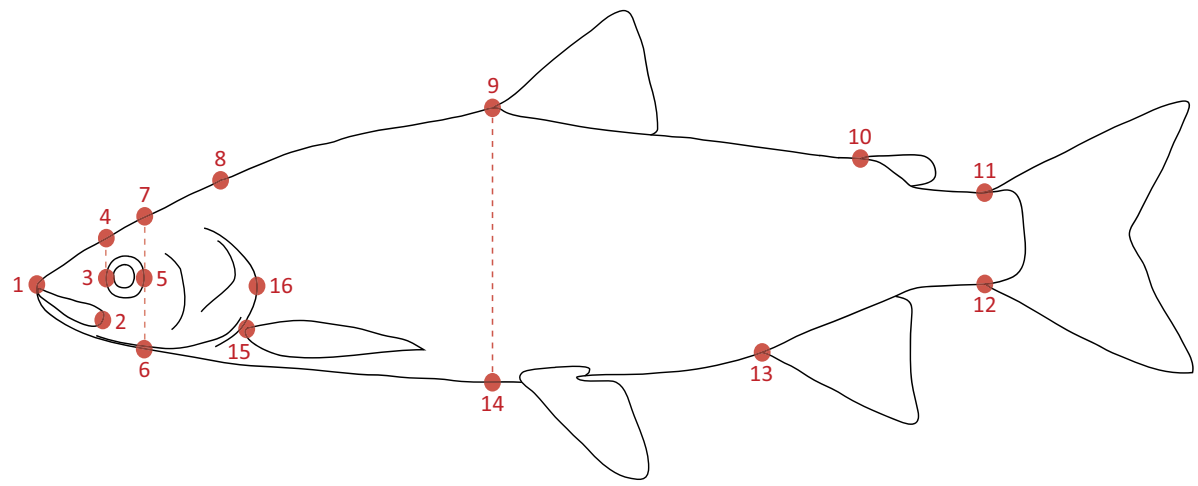

Fig. 2 Landmarks used for geometric morphometrics analysis of fry and adult C. lavaretus shape: (1) tip of snout; (2) posterior of maxilla; (3) anterior of eye; (4) dorsal surface perpendicular to (3); (5) posterior of eye; $(6,7)$ dorsal and ventral surfaces perpendicular to $(5)$; (8) dorsal posterior of skull; (9) anterior insertion of dorsal fin; $(10)$ anterior insertion of adipose fin; $(11,12)$ dorsal and ventral junctions of caudal fin; (13) anterior insertion of anal fin; (14) ventral surface perpendicular to (9); (15) anterior insertion of pectoral fin; (16) posterior tip of operculum. Perpendicular alignments between landmarks are indicated with broken lines

Nested Procrustes ANOVAs were performed with 1000-round randomized residual permutation procedures. To compare whitefish morphologies between lakes of origin, where allometric slopes were parallel, a reduced model tested the effect of log centroid size on shape (compiled from Procrustes coordinates), and a full model added population as an explanatory variable. These models allowed pairwise comparisons of least-squares means distances between populations or families. Where slopes were not parallel, the reduced model tested the effects of slope and either population or family on shape, while the full model added the interaction between either slope and population or slope and family. These models allowed pairwise comparisons of slope vectors.

\section{Results}

\section{Alevins}

After lunate distortion in PC1 was accounted for, the PCA (Fig. 3) showed that alevins with high PC1 scores (27.6\% PVE) had shallower bodies, longer heads, larger eyes and smaller yolk sacs than those with low scores. High PC2 scores (17.2\% PVE) revealed deeper bodies and heads, and larger yolk sacs than low scores. Alevins originating from Loch Lomond were found to show rather less variation than those from Loch Sloy.

Allometric slopes were parallel between the two lakes of origin $(p=0.172$, supporting the null hypothesis of parallel slopes). The full model of the Procrustes ANOVA showed lake of origin to have a significant effect on alevin shape $\left(F_{1,72}=3.527, R^{2}=0.049\right.$, $Z=2.884, p=0.001$ ), and there was clear differentiation between the Loch Lomond and Loch Sloy alevins on the basis of morphology alone (LS means distance $=0.015, Z=3.662$, $p=0.001)$. Characteristically, Loch Lomond alevins had larger yolk sacs and shallower bodies compared to those from Loch Sloy, while Loch Sloy alevins showed more pronounced definition to the dorsal posterior of the skull (Fig. 4). 


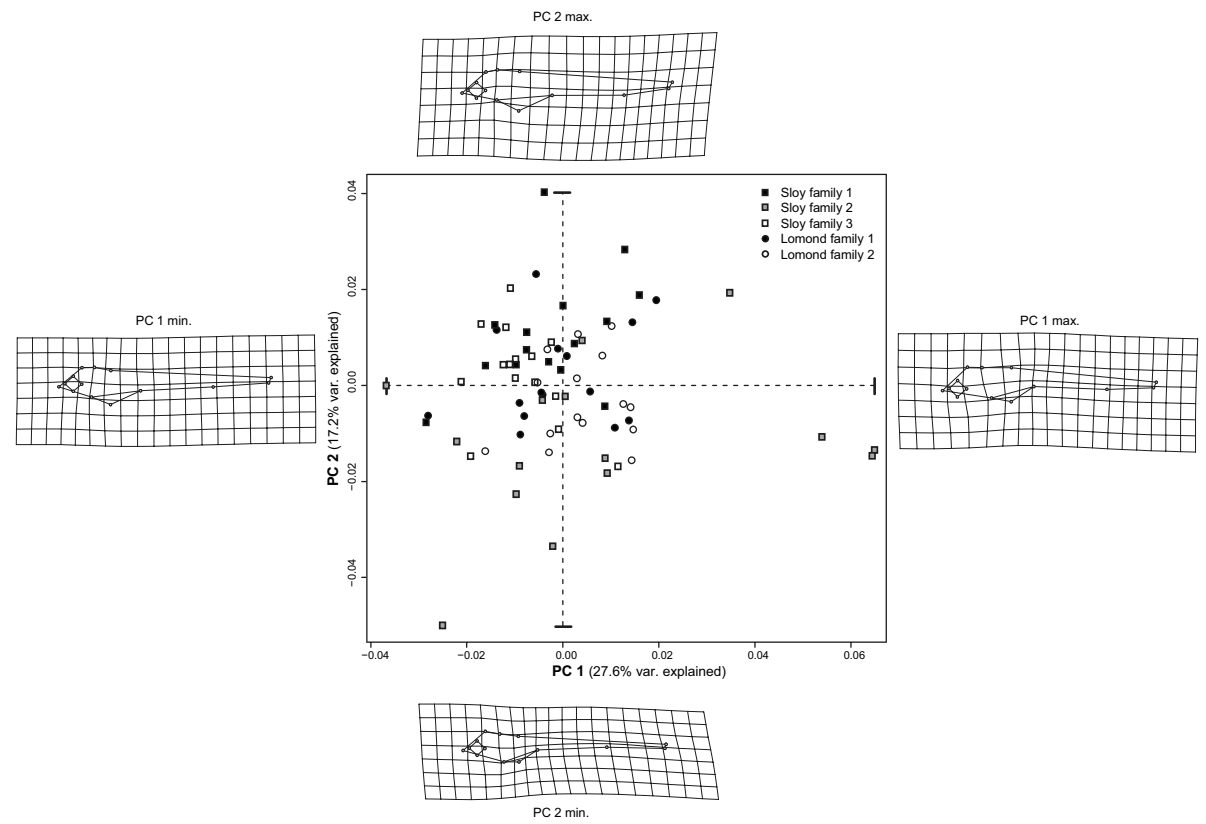

Fig. 3 PCA describing the shapes of whitefish alevins from two families originating from Loch Lomond and three from Loch Sloy. Wireframe deformation grids represent extremes along each axis

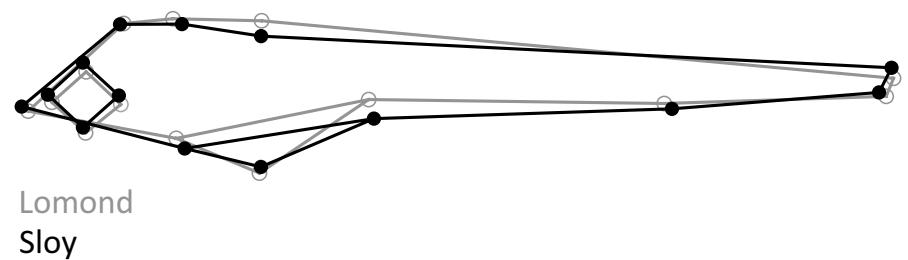

Fig. 4 Average shape of whitefish alevins originating in Loch Sloy (black) superimposed upon the average shape of those from Loch Lomond (grey). Loch Sloy alevins characteristically exhibited smaller yoke sacs, deeper bodies, and more pronounced definition to the dorsal posterior of the skull than the Loch Lomond alevins. For clarity, outline differences are exaggerated in scale by a factor of ten

At a family level, slopes were not parallel $\left(F_{4,65}=2.132, R^{2}=0.090, Z=3.723\right.$, $p=0.001$ ). Between Loch Sloy families, slopes differed significantly (Table 1). However, correlations between the slope vectors of the Loch Lomond families were not significant $(p=0.179)$.

\section{Fry}

Fry with high PC1 scores (34.7\% PVE) showed, after accounting for lunate distortion, longer heads, jaws and, especially, caudal peduncles than those with low scores. Deeper heads and bodies, and more ventrally positioned mouths were characteristic of higher PC2 scores (20.5\% PVE). Fry originating from Loch Lomond tended more 
Table 1 Pairwise comparisons between whitefish alevin families originating from Lochs Lomond and Sloy: correlations between slope vectors, effect sizes (in bold), and $p$ values (in italics)

\begin{tabular}{lrrrr}
\hline & Lomond 1 & Lomond 2 & Sloy 1 & Sloy 2 \\
\hline Lomond 2 & -0.171 & & & \\
& $\mathbf{1 . 0 0 5}$ & & & \\
& 0.179 & & & \\
Sloy 1 & -0.331 & 0.012 & & \\
& $\mathbf{1 . 7 4 2}$ & $\mathbf{0 . 9 2 8}$ & & \\
& 0.065 & 0.181 & & \\
Sloy 2 & 0.127 & 0.012 & -0.469 & \\
& $\mathbf{0 . 6 2 4}$ & $\mathbf{1 . 3 8 5}$ & $\mathbf{4 . 0 1 9}$ & \\
& 0.246 & 0.110 & $0.005^{*}$ & \\
Sloy 3 & 0.328 & -0.043 & -0.150 & -0.363 \\
& $\mathbf{- 0 . 5 1 1}$ & $\mathbf{0 . 2 2 4}$ & $\mathbf{1 . 1 6 7}$ & $\mathbf{2 . 0 5 2}$ \\
& 0.668 & 0.383 & 0.149 & $0.046^{*}$ \\
\hline
\end{tabular}

Significant differences are marked with an asterisk

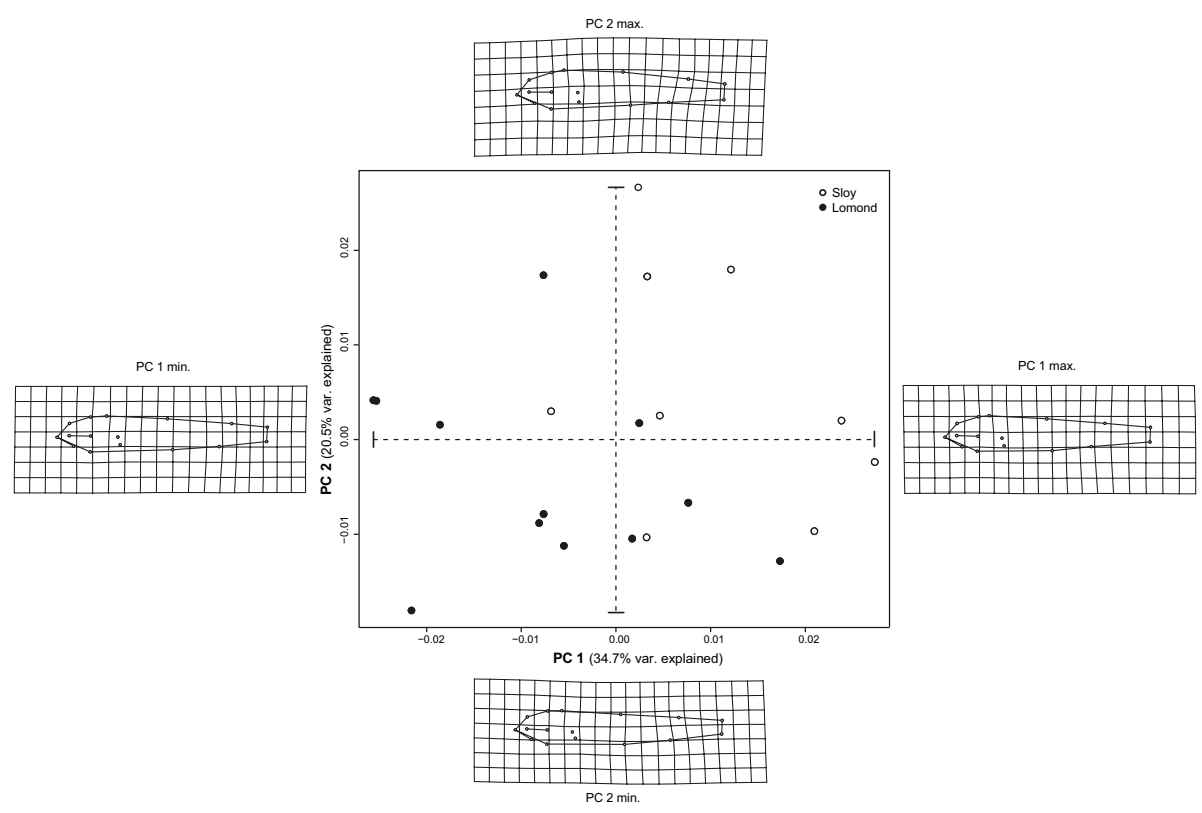

Fig. 5 PCA describing the shapes of whitefish fry originating from Loch Lomond and Loch Sloy. Wireframe deformation grids represent extremes along each axis

towards low PC1 and PC2 scores than did those from Loch Sloy (Fig. 5). Allometric slopes were not parallel $\left(F_{1,17}=2.057, R^{2}=0.086, Z=2.127, p=0.016\right)$, and correlations between slope vectors significantly differentiated fry by their lake of origin $(-0.506, Z=2.767, p=0.005)$. 


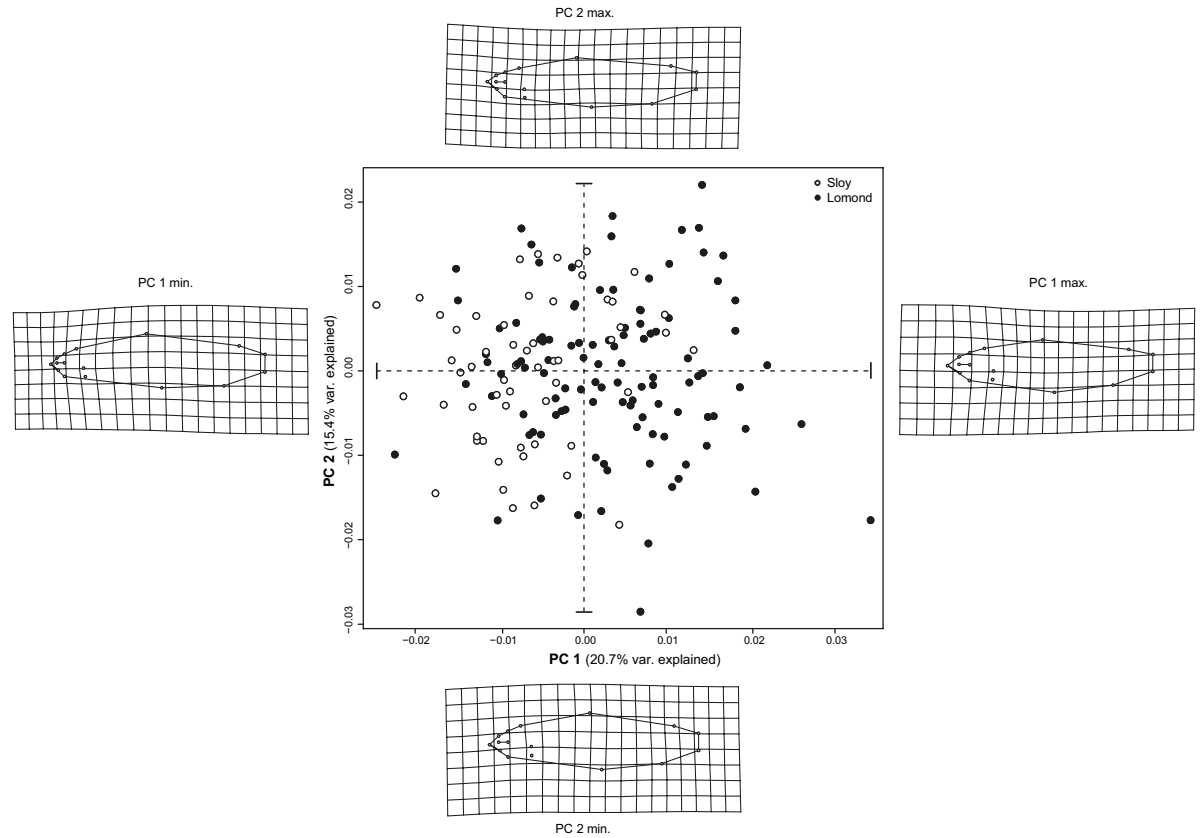

Fig. 6 PCA describing the shapes of whitefish adults originating from Loch Lomond and Loch Sloy. Wireframe deformation grids represent extremes along each axis

\section{Adults}

Lunate distortion was accounted for in the PCA for adults (Fig. 6) at PC1. Whitefish with high PC1 scores (20.2\% PVE) showed shorter, less tapered heads and jaws, and smaller eyes than those with low scores; while high PC2 scores (15.4\% PVE) indicated deeper heads and bodies, and more ventrally positioned mouths than low scores. Fish caught in Loch Lomond tended to higher PC1 scores than did those from Loch Sloy. The allometric slopes of the two populations were not parallel $\left(F_{1,161}=2.211, R^{2}=0.013, Z=2.183\right.$, $p=0.010$ ), and the pairwise comparison of populations showed clear differentiation in the correlation between slope vectors $(0.184, Z=2.248, p=0.031)$.

\section{Discussion}

The significant differences in morphology seen between adult whitefish from the donor and refuge populations (Loch Lomond and Loch Sloy, respectively) in the present study accord with those found by Etheridge et al. (2010). This was unaffected by the discrepancies in the number of generations since the translocation between the two studies (four for Etheridge et al. 2010; and between four and six for the present study). Although heritability of morphological traits was not tested directly, and other explanations are possible and examined below, this study suggests that the differences in adult morphology between populations are, at least in part, inherited. This is distinct from the suggestion by Etheridge et al. (2010) 
that the differences may largely be due to environmentally induced plastic changes in phenotype (sensu West-Eberhard 2005; Ghalambor et al. 2007).

Unfed alevins originating from eggs of whitefish from each of the two lakes, incubated in a common environment, showed clear morphological differences from the moment of hatching. Fry raised in a common environment, and thus unable to exhibit a differential environmental response (Alexander and Adams 2004), also still showed marked differences in phenotype depending upon their lake origin. Of course, evidence of the heritability of morphological traits presented here does not preclude a role for plasticity in also shaping the morphologies of whitefish in these lakes; plasticity may indeed overlay the effects of inheritance, and drive further differences during ontogeny (Fusco and Minelli 2010; Parsons et al. 2011). However, it is clear that a major driver of the morphological divergence between whitefish in the wild from the donor and conservation refuge populations is that of inherited differences.

Although not tested directly here, there are several routes through which change through inheritance may have arisen during the translocation in Loch Sloy. The first is that the observed differences between juveniles from the two populations reared in the common garden study may be the result of differing parental effects, in which the parents' phenotypes influence those of offspring beyond the direct effects of genes (Räsänen and Kruuk 2007). This may take the form of gamete provisioning, in which the size, lipid content and/ or fatty acid composition of ova can play a role in eventual alevin phenotype and fitness (Wiegand et al. 2007; Johnston 2018; Shaw et al. 2018). Alternatively, transgenerational epigenetic effects may be responsible for the divergent phenotypes. Under such effects, the environment to which the parents of the offspring used in this experiment were exposed may have had a direct epigenetic effect on the offspring in this experiment (True et al. 2004; Heard and Martienssen 2014; Spadafora 2018). However, given the small sample sizes, particularly of fry, the likelihood of either of these transgenerational possibilities is difficult to assess.

Otherwise, it may be genuine functional genetic divergence resulting from differential selection pressures in the two lakes, that has resulted in the phenotypic divergence of the two whitefish populations. Significant genetic divergence has been seen before in similar translocation circumstances: after discounting founder effects and genetic drift, involving a closely related coregonid species, vendace ( $C$. albula), this occurred in less than a century (Vuorinen et al. 1991). Recently, evidence of at least one private microsatellite allele in the Loch Sloy population has been found, which is presumed to have arisen through genetic mutation (Præbel et al. 2019). In contradistinction to genetic drift, genes underlying traits under selection, whether mutation-order or ecologically mediated, can be rapid, as natural selection leads alleles to fixation (Schluter 2009), which would be not observed using neutral markers (c.f. Thompson et al. 2008).

Another possibility is that genetic differences are the result of founder effects resulting from the translocation process itself (e.g. Hauser et al. 1995; Weeder et al. 2005). This would be likely to occur if the genetic diversity of the whitefish used during the translocation were restricted. However, attention was given to maximise genetic diversity in those fish used to create the refuge population (Maitland and Lyle 1992, 2013). Although it does not address genes underlying selected traits, the evidence from selection-neutral genetic markers is that a very substantive proportion of genetic variation was captured during the process of forming the conservation refuge site (Etheridge et al. 2010; Præbel et al. 2019). Therefore, it seems unlikely that founder effects are wholly responsible for the differences described here, although they cannot be entirely discounted. 
Similarly, genetic drift is also unlikely to be a major driver of the differences described here, although, again, this cannot be entirely discounted, as genes underlying traits under selection have not been investigated. There is, however, evidence of only a very small loss of allelic richness in the Loch Sloy population compared to that of Loch Lomond using selection-neutral markers (Thompson et al. 2008). The time has also been rather short for a non-selective process to act: only five or six generations since the translocation over which drift might have had an effect (Brown et al. 1991), thus making drift as the sole explanation also unlikely.

Because an exact replication of the environmental conditions of the donor lake in the refuge site is, in practice, impossible (Etheridge et al. 2010), it is reasonable to suppose that there is at least some differential selection pressure exerted on the two whitefish populations, and that the resultant genetic responses may be adaptive. It has been repeatedly noted that differing foraging habitats, particularly those across benthic to pelagic niches can stimulate adaptive phenotypic responses in many species of fish in recently glaciated lakes (e.g. Smith and Skúlason 1996). Morphology, especially, correlates strongly with diet (Adams and Huntingford 2002; Kahilainen and Østbye 2006; Østbye et al. 2005). The transgenerational traits of Loch Lomond whitefish such as a slender head and narrower body are associated with a pelagic feeder (Etheridge et al. 2012), and Loch Lomond whitefish are known to feed primarily on zooplankton in the pelagic (Pomeroy 1991). In contrast, the more robust head and body of Loch Sloy whitefish are more characteristic of benthic feeders (Parsons and Robinson 2007; McPhee et al. 2012). Together, divergent morphologies along the benthic and pelagic habitats are consistent with whitefish in the two lakes exploiting different niches that, in turn, result in different selection pressures on each population.

Such a divergence of the refuge from the donor population has considerable consequences for conservation translocations. The raison d'être of a conservation refuge is to protect the potential diversity of the donor population to the extent that members of the refuge population could be reintroduced to the original site without a reduction in fitness (Stockwell et al. 1996; Moritz 1999; Etheridge et al. 2010). The findings here suggest that this goal is likely to be significantly eroded. Had the morphological differences of the Loch Sloy whitefish compared to those from Loch Lomond been just the result of plastic responses of the refuge population to a new environment (sensu West-Eberhard 1989), then such conservation aims would not be impaired (Etheridge et al. 2010), assuming no further evolutionary change in the donor population. However, significant evolutionary divergence between donor and refuge populations, through whatever mechanism, undermines the validity of a refuge conservation approach. This study demonstrates that it may not be possible to initiate a conservation translocation into another habitat, no matter how carefully executed, without the possibility of inducing directional selection on the translocated population, thereby affecting its phenotypic and/or genetic diversity, as it establishes in the refuge.

A final surprising element of this study was the differences in morphology between individual families of alevins, particularly among those originating in Loch Sloy. They may represent differential phenotypic responses to a new environment, potentially with alternative resources that effect disruptive selection (Skúlason and Smith 1995; Robinson and Parsons 2002; Crispo et al. 2006). However, the greater variance found amongst the Loch Sloy alevins was at odds with predictions that larger, more heterogeneous ecosytems, such as Loch Lomond, should harbour greater phenotypic variety (Recknagel et al. 2017). Of course, this could simply be due to natural population variance. In any 
case, with only five families sampled incipient resource polymorphism must remain, for now, merely a hypothesis for future study.

Acknowledgements The assistance of Alexander Lyle and Jessica Rodger in sample collection, and Navin Chahal in husbandry, is gratefully acknowledged.

\section{Compliance with ethical standards}

Conflict of interest All authors declare that they have no conflict of interest.

Open Access This article is distributed under the terms of the Creative Commons Attribution 4.0 International License (http://creativecommons.org/licenses/by/4.0/), which permits unrestricted use, distribution, and reproduction in any medium, provided you give appropriate credit to the original author(s) and the source, provide a link to the Creative Commons license, and indicate if changes were made.

\section{References}

Adams CE, Huntingford FA (2002) The functional significance of inherited differences in feeding morphology in a sympatric polymorphic population of Arctic charr. Evol Ecol 16:15-25

Adams CE, Huntingford FA (2004) Incipient speciation driven by phenotypic plasticity? Evidence from sympatric populations of Arctic charr. Biol J Linn Soc 81:611-618

Adams CE, Maitland PS (1998) The ruffe population of Loch Lomond, Scotland: its introduction, population expansion, and interaction with native species. J Great Lakes Res 24(2):249-262

Adams CE, Tippett R (1991) Powan, Coregonus lavaretus (L.), ova predation by newly introduced ruffe, Gymnocephalus cernuus (L.), in Loch Lomond, Scotland. Aquac Res 22(2):239-246

Adams CE, Lyle AA, Dodd JA, Bean CW, Winfield IJ, Gowans ARD, Stephen A, Maitland PS (2014) Translocation as a conservation tool: case studies from rare freshwater fishes in Scotland. Glasg Nat 26(1):17-24

Adams CE, Bean CW, Dodd JA, Down A, Etheridge EC, Gowans ARD, Hooker OE, Knudsen R, Lyle AA, Winfield IJ, Præbel K (2016) Inter and intra-population phenotypic and genotypic structuring in the European whitefish Coregonus lavaretus, a rare freshwater fish in Scotland. J Fish Biol 88:580-594

Adams DC, Collyer ML, Kaliontzopoulou A (2019) Geomorph: software for geometric morphometric analysis. R package version 3.1.0. https://cran.r-project.org/package=geomorph

Alexander GD, Adams CE (2004) Exposure to a common environment erodes inherited between-population trophic morphology differences in Arctic charr. J Fish Biol 64:253-257

Appleberg M, Berger H-M, Hesthagen T, Kleiven E, Kurkilahti M, Raitaniemi J, Rask M (1995) Development and intercalibration of methods in nordic freshwater fish monitoring. Water Air Soil Pollut 85(2):401-406

Beaumont AR, Bray J, Murphy JM, Winfield IJ (1995) Genetics of whitefish and vendace in England and Wales. J Fish Biol 46:880-890

Bernatchez L, Wilson CC (1998) Comparative phylogeography of Nearctic and Palearctic fishes. Mol Ecol 7:431-452

Brown EAR, Scott DBC (1994) Life histories of the powan, Coregonus lavatretus (L.) (Salmonidae, Corgoninae) of Loch Lomond and Loch Eck. Hydrobiologia 290:121-133

Brown EAR, Finnigan N, Scott DBC (1991) A life table for powan, Coregonus lavaretus (L.) in Loch Lomond, Scotland: a basis for conservation strategy. Aquat Conserv Mar Freshw Ecosyst 1:183-187

Carvalho GR (1993) Evolutionary aspects of fish distribution: genetic variability and adaptation. J Fish Biol 43(Suppl. A):53-73

Collyer ML, Adams DC (2019) RRPP: linear model evaluation with randomized residuals in a permutation procedure. https://cran.r-project.org/web/packages/RRPP. Accessed 23 Mar 2019

Crispo E, Bentzen P, Reznick DN, Kinnison MT, Hendry AP (2006) The relative influence of natural selection and geography on gene flow in guppies. Mol Ecol 15:49-62

Draghi JA, Whitlock MC (2012) Phenotypic plasticity facilitates mutational variance, genetic variance, and evolvability along the major axis of environmental variation. Evolution 66(9):2891-2902 
Etheridge EC, Bean CW, Maitland PS, Adams CE (2010) Morphological and ecological responses to a conservation translocation of powan (Coregonus lavaretus) in Scotland. Aquat Conserv Mar Freshw Ecosyst 20:274-281

Etheridge EC, Bean CW, Maitland PS, Ballantyne S, Adams CE (2012) Discontinuous infraspecific variation in ecological and morphological traits has consequences for conservation of powan (Coregonus lavaretus) in Scotland. Adv Limnol 63:505-517

Fusco G, Minelli A (2010) Phenotypic plasticity in development and evolution: facts and concepts. Phil Trans R Soc B 365:547-556

Ghalambor CK, McKay JK, Carroll SP, Reznick DN (2007) Adaptive versus non-adaptive phenotypic plasticity and the potential for contemporary adaptation in new environments. Funct Ecol 21:394-407

Gíslason D, Ferguson MM, Skúlason S, Snorrason SS (1999) Rapid and coupled phenotypic and genetic divergence in Icelandic Arctic charr (Salvelinus alpinus). Can J Fish Aquat Sci 53:2229-2234

Hartley SE (1995) Mitochondrial DNA analysis distinguishes between British populations of the whitefish. J Fish Biol 47(Suppl. A):145-155

Hauser L, Carvalho GR, Pitcher TJ (1995) Morphological and genetic differentiation of the African clupeid Limnothrissa miodon 34 years after its introduction to Lake Kivu. J Fish Biol 47(Suppl. A):127-144

Heard E, Martienssen RA (2014) Transgenerational epigenetic inheritance: myths and mechanisms. Cell 157(1):95-109

Hendry AP (2016) Key questions on the role of phenotypic plasticity in eco-evolutionary dynamics. J Hered 107(1):25-41

Hooker OE, Barry J, Van Leeuwen TE, Lyle A, Newton J, Cunningham P, Adams CE (2016) Morphological, ecological and behavioural differentiation of sympatric profundal and pelagic Arctic charr (Salvelinus alpinus) in Loch Dughaill Scotland. Hydrobiologia 783(1):209-221

Januszkiewicz AJ, Robinson BW (2007) Divergent walleye (Sander vitreus)-mediated inducible defences in the centrarchid pumpkinseed sunfish (Lepomis gibbosus). Biol J Linn Soc 90:25-36

Johnston TA (2018) Egg size and lipid content of lake trout (Salvelinus namaycush) in the wild and in captivity. Can J Fish Aquat Sci. https://doi.org/10.1139/cjfas-2017-0408

Kahilainen K, Østbye K (2006) Morphological differentiation and resource polymorphism in three sympatric whitefish Coregonus lavaretus (L.) forms in a subarctic lake. J Fish Biol 68:63-79

Klemetsen A (2013) The most variable vertebrate on earth. J Ichthyol 53(10):781-791

Lema SC, Nevitt GN (2006) Testing an ecophysiological mechanism of morphological plasticity in pupfish and its relevance to conservation efforts for endangered Devils Hole pupfish. J Exp Biol 209:3499-3509

Levis NA, Pfennig DW (2016) Evaluating 'plasticity-first' evolution in nature: key criteria and empirical approaches. Trends Ecol Evol 31(7):563-574

Loch Lomond Fisheries Trust (2018) Educate and inform: Lomond in the classroom. http://www.llft.org/whatwe-do/educate-and-inform/. Accessed Apr 2019

Lundsgaard-Hansen B, Matthews B, Vonlanthen P, Taverna A, Seehausen O (2013) Adaptive plasticity and genetic divergence in feeding efficiency during parallel adaptive radiation of whitefish (Corgonus spp.). J Evol Biol 26:483-498

Maitland PS, Lyle AA (1992) Conservation of freshwater fish in the British Isles: proposals for management. Aquat Conserv Mar Freshw Ecosyst 2:165-183

Maitland PS, Lyle AA (2013) Ex situ and in situ approaches, including assisted reproduction, for the conservation of native species of charr (Salmindae) and whitefish (Coregonidae) in Scotland. Int Zoo Yb 47:129-139

Matute DR (2013) The role of founder effects on the evolution of reproductive isolation. J Evol Biol 26:2299-2311

McPhee MV, Noakes DLG, Allendorf FW (2012) Developmental rate: a unifying mechanism for sympatric divergence in postglacial fishes. Curr Zool 58:21-34

Mitteroecker P, Gunz P (2009) Advances in geometric morphometrics. Evol Biol 39:235-247

Moritz C (1999) Conservation units and translocations: strategies for conserving evolutionary processes. Hereditas 130:217-228

Nosil P (2012) Ecological speciation. Oxford University Press, Oxford

Østbye K, Næsje TF, Bernatchez L, Sandlund OT, Hindar K (2005) Morphological divergence and origin of sympatric populations of European whitefish (Coregonus lavaretus L.) in Lake Femund, Norway. J Evol Biol 8:683-702

Parsons KJ, Robinson BW (2006) Replicated evolution of integrated plastic responses during early adaptive divergence. Evolution 60(4):801-813

Parsons KJ, Robinson BW (2007) Foraging performance of diet-induced morphotypes in pumpkinseed sunfish (Lepomis gibbosus) favours resource polymorphism. J Evol Biol 20:673-684 
Parsons KJ, Sheets HD, Skúlason S, Ferguson MM (2011) Phenotypic plasticity, heterochrony and ontogenetic repatterning during juvenile development of divergent Arctic charr (Salvelinus alpinus). J Evol Biol 24:1640-1652

Pfennig DW, Wund MA, Snell-Rood EC, Cruickshank T, Schlichting CD, Moczek AP (2010) Phenotypic plasticity's impacts on diversification and speciation. Trends Ecol Evol 25(8):459-467

Pomeroy PP (1991) A comparative assessment of temporal variation in diet of powan, Coregonus lavaretus (L.), from Loch Lomond and Loch Eck, Scotland, UK. J Fish Biol 38:457-478

Præbel K, Bean CW, Dodd JA, Etheride EC, Gowans ARD, Knudsen R, Lyle AA, Maitland PS, Winfield IJ, Adams CE (2019) Allelic losses and gains of a high conservation value fish, Coregonus lavaretus. Available at SSRN: https://papers.ssrn.com/sol3/papers.cfm?abstract_id=3358962

Price TD, Qvarnström A, Irwin DI (2003) The role of phenotypic plasticity in driving genetic evolution. Proc R Soc Lond B 270:1433-1440

R Core Team (2019) R: a language and environment for statiscal computing. R Foundation for Statistical Computing, Vienna. https://www.R-project.org/

Räsänen K, Kruuk LEB (2007) Maternal effects and evolution at ecological time-scales. Funct Ecol 21:408-421

Recknagel H, Hooker OE, Adams CE, Elmer KR (2017) Ecosystem size predicts eco-morphological variability in a postglacial diversification. Ecol Evol 7:5560-5570

Robinson BW, Parsons KJ (2002) Changing times, spaces, and faces: tests and implications of adaptive morphological plasticity in the fishes of northern postglacial lakes. Can J Fish Aquat Sci 59:1819-1833

Rohlf FJ (2017a) tpsDig2 version 2.30. Department of Ecology and Evolution, State University, Stony Brook, New York

Rohlf FJ (2017b) tpsUtil version 1.74. Department of Ecology and Evolution, State University, Stony Brook, New York

Rottman RW, Shiremann JV (1988) Hatching jar that is inexpensive and simple to assemble. Prog Fish Cult 50:57-58

Schluter D (2000) The ecology of adaptive radiation. Oxford University Press, New York

Schluter D (2009) Evidence for ecological speciation and its alternative. Science 323:737-741

Schneider RF, Meyer A (2017) How plasticity, genetic assimilation and cryptic genetic variation may contribute to adaptive radiations. Mol Ecol 26:330-350

Shaw SL, Sass GG, VanDeHey JA (2018) Maternal effects better predict walleye recruitment in Escanaba Lake, Wisconsin, 1957-2015: implications for regulations. Can J Fish Aquat Sci. https://doi.org/10.1139/cjfas $-2017-0318$

Skúlason S, Smith TB (1995) Resource polymorphisms in vertebrates. Trends Ecol Evol 10(9):366-370

Smith TB, Skúlason S (1996) Evolutionary significance of resource polymorphism in fishes, amphibians, and birds. Annu Rev Ecol Syst 27:111-133

Spadafora C (2018) The "evolutionary field" hypothesis. Non-Mendelian transgenerational inheritance mediates diversification and evolution. Prog Biophys Mol Biol 134:27-37

Stockwell CA, Mulvey M, Vinyard GL (1996) Translocations and the preservation of allelic diversity. Conserv Biol 10(4):1133-1141

Takács P, Vitál Z, Ferincz Á, Staszny Á (2016) Repeatability, reproducibility, separative power and subjectivity of different fish morphometric analysis methods. PLoS ONE 11(6):e0157890

Thompson C, Verspoor E, Prodhöl P, Adams C (2008) Further development of novel microsatellite markers for biodiversity assessment of vendace and coregonid populations. Scottish Natural Heritage Commissioned Report (ROAME No. R07AC618B), Scottish Natural Heritage, Edinburgh

Thorstad EB, Whoriskey F, Rikardsen AH, Aarestrup K (2011) Aquatic nomads: the life and migrants of the Atlantic Salmon. In: Aas $\varnothing$, Einum S, Klemetsen A, Skurdal J (eds) Atlantic salmon ecology. Wiley, Chichester, pp 1-32

True HL, Berlin I, Lindquist SL (2004) Epigenetic regulation of translation reveals hidden genetic variation to produce complex traits. Nature 431:184-187

Valentin AE, Penin X, Chanut J-P, Sévegny J-M, Rohlf FJ (2008) Arching effect on fish body shape in geometric morphometric studies. J Fish Biol 73:623-638

Vonlanthen P, Roy D, Hudson AG, Largiadèr CR, Bittner D, Seehausen O (2009) Divergence along a steep ecological gradient in lake whitefish (Coregonus sp.). J Evol Biol 22:498-514

Vuorinen J, Næsje TF, Sandlund OT (1991) Genetic changes in a vendace Coregonus albula (L.) population, 92 years after introduction. J Fish Biol 39(Suppl. A):193-201

Weeder JA, Marshall AR, Epifanio JM (2005) An assessment of population genetic variation in chinook salmon from seven Michigan rivers 30 years after introduction. N Am J Fish Manag 25(3):861-875

West-Eberhard MJ (1989) Phenotypic plasticity and the origins of diversity. Annu Rev Ecol Syst 20:249-278

West-Eberhard MJ (2005) Developmental plasticity and the origin of species differences. PNAS 2(Suppl.):6543-6549 
Wiegand MD, Johnston TA, Leggett WC, Watchorn KE, Ballevona AJ, Porteous LR, Casselman JM (2007) Contrasting strategies of ova lipid provisioning in relation to maternal characteristics in three walleye (Sander vitreus) populations. Can J Fish Aquat Sci 64:700-712

Publisher's Note Springer Nature remains neutral with regard to jurisdictional claims in published maps and institutional affiliations. 